\title{
Value of Diffusion Weighted Magnetic Resonance Imaging (DW-MRI) and ADC in Evaluation of Urinary Bladder Carcinoma
}

\author{
MONA A.M.A. NAGI, M.D.*; HANAA A. AHMED, M.D.* and DHURGHAM HAYDER WALI, M.Sc.** \\ The Department of Radiology, Faculty of Medicine, Ain-Shams* and Dhi-Qar** Universities
}

\begin{abstract}
Background: Urinary bladder cancer is the fourth commonest among males and the tenth among females. It has a high recurrence rate necessitating proper initial management. MRI is a very valuable imaging tool with high tissue contrast and multi-planar imaging abilities thus allowing better tissue characterization.

Aim of Study: Is to evaluate the value of diffusion weighted magnetic resonance imaging (MRI-DWI) in the diagnosis and staging of urinary bladder carcinoma, with pathological diagnosis taken as the reference.

Patients and Methods: In this study, 40 patients with suspected urinary bladder masses performed pelvic MR imaging. All patients were scheduled for variable MR sequences including T2WIs and DWIs.

Results: Regarding the detection of urinary bladder carcinoma the sensitivity, specificity, and accuracy for differentiating superficial from invasive tumors using $\mathrm{T} 2$ images alone and combined use of T2 and DW images were $62.5 \%, 66.7 \%$, $63.2 \%$ and $100 \%, 100 \%, 100 \%$ respectively.

Conclusion: DW-MRI is a safe, quick accurate sequence that can accurately detect and local stage urinary bladder carcinoma. In addition, DW images can predict the histological grade of the tumor decreasing the need for biopsy.
\end{abstract}

Key Words: MRI (magnetic resonance imaging) - DWI (diffusion weighted images).

\section{Introduction}

BLADDER cancer (BC) is one of the commonest malignancies in Egypt [1]. The ability to differentiate benign urinary bladder (UB) lesions from malignant lesions as well as accurate detection of the histo-pathological type and tumor grade of malignant lesions is critical for accurate therapeutic planning [2].

Correspondence to: Dr. Mona A.M.A. Nagi, E-Mail:mona.babydoc@yahoo.com.
Until now, the trans-urethral biopsy (TUR biopsy) remains the gold standard for diagnosing, staging and determining the grade of $\mathrm{BC}$, however it is considered as an invasive technique with hazards especially in patients with hemorrhagic tendencies [3].

DCE MRI requires the use of gadolinium-based contrast agents, which should be used with caution in cases with renal impairment. Diffusion weighted imaging (DWI) has been suggested as a modality for diagnosis, staging, grading and assessment of treatment response in $\mathrm{BC}$ [4] .

DW MRI depends on the mobility of water molecules (Brownian motion) inside the tissues, to generate an image contrast [5]. In malignant lesions with a high compact cellularity with intact cell membranes, the diffusion is restricted. However, it is less restricted in areas of low cellular density [6]

The aim of this work is to assess ability to use DWI to diagnose, stage and determine the grade of BC.

\section{Patients and Methods}

Patients: This retrospective study was done at El-Demerdash Hospital that included 40 patients in whom bladder masses were suspected either clinically or by U/S. The patients were referred to the Radiology Department for further MRI evaluation with DWIs. Written consents were all patients to participate in this study, according to the rules of ethical committee.

\section{Inclusion criteria:}

- Age range: 30-75 years.

- Patients with urinary bladder masses detected by other imaging modalities. 


\section{Exclusion criteria:}

- History of urinary tract trauma.

- Contraindications to MR imaging (e.g., pacemaker or metallic prostheses).

\section{Technique of MRI examination:}

\section{Patient preparation:}

- Full history was taken pre-procedural with emphasis on any history of trauma, any bleeding tendencies or anticoagulation therapy.

- All patients were requested to fast for 6 hours before the examination of urinary tract.

- Patients were instructed to start drinking water without urination one hour before the MR imaging examination to allow average distention of the urinary bladder.

- No special bowel preparation was required.

\section{MRI technique:}

- MRI studies were performed on 1.5 T MRI (Achieva, Philips medical system), using body coil (phased array coil). All the patients were imaged in the supine position with head directed towards the magnet (HFS).

- Proper bladder fullness was checked on localizer images, and the examination was postponed if the bladder was not properly full.

- Turbo spin-echo T2-weighted images were obtained (repetition time msec/echo time msec, 2250-3500/90-100; bandwidth, 20-83kHz; matrix, 256 x 256; section thickness, 4-6mm; intersection gap, $1-2 \mathrm{~mm}$; field of view, $20 \mathrm{~cm}$ ). T2-weighted images were assessed in the axial planes mainly but some cases required sagittal and coronal planes for better characterization.

- Then, with the patient free breathing, DW images were obtained in the axial plane by using a body coil and a monodirectional gradient multisection fast spin-echo echoplanar sequence (repetition time msec/echo time msec 3500-4500/6070; bandwidth, $142 \mathrm{kHz}$; matrix, 256 x 256; section thickness, 4-6mm; intersection gap, 1-2mm; field of view, $36 \mathrm{~cm}$; signals acquired with $b$-values of 0,400 and $800 \mathrm{sec} / \mathrm{mm}^{2}$ ). Thirty to 55 sections were obtained in 60-120 seconds to cover the pelvis.

- T1-weighted fast field-echo images with a water-selective excitation technique (repetition time msec/echo time msec 400-460/10-15; flip angle, $20^{\circ}$; matrix, $256 \times 256$; section thickness, 4-6mm; intersection gap, 1-2; field of view, $36 \mathrm{~cm}$; number of sections, 24-27; acquisition time, 2630 seconds were obtained.

ADC maps were generated in the tumors that were large enough $(>5 \mathrm{~mm})$ to contain the region of interest (ROI). The ADC values were calculated to evaluate the degree of diffusion and are expressed in $\left(\mathrm{x}^{-3}\right)$ square millimeters per second.

Image Interpretation: All MR image sets were interpreted independently from all histo-pathological information. There were two image sets: T2weighted images alone and T2-weighted plus DW images. Diagnostic accuracy of staging with MR images was compared to the pathologic stage.

All MR image sets were interpreted independently by two radiologist 5 and 10 year experience who were blinded from all histopathological information.

\section{Analysis of data:}

Statistical analysis: Statistical Package for Social Science (SPSS 15.0.1 for windows; SPSS Inc, Chicago, IL, 2001) was used. Data was presented as Mean and Standard Deviation $( \pm S D)$ for quantitative parametric data, and Median and Interquartile range for quantitative non-parametric data. $t$-test was used to compare between benign and malignant bladder lesions. ROC curve was used to determine the cutoff value of ADC.

\section{Results}

Our study included 40 patients with age ranging from 30 to 75 years (mean age: $52.85 \pm 13.81$ ). 18 of our patients $(45 \%)$ were $\leq 50$ years and 22 patients $(55 \%)$ were $>50$ years old. Out of 40 patients, 8 patients were females $(20 \%)$ and $32(80 \%)$ were males. (Table 1).

$90 \%$ of the cases complained of hematuria ( 36 cases) while only $10 \%$ with irregular vaginal bleeding at presentation.

The lesion size was $\leq 5 \mathrm{~cm}$ in $50 \%$ of the cases and $>5 \mathrm{~cm}$ in the other $50 \%$.

On $\mathrm{T} 2$ weighted images, heterogeneous signal intensity was found in 2 cases (5\%), iso-intense signal intensity was found in 8 cases (20\%), hypo signal intensity was found in 6 cases $(15 \%)$ and hyper signal intensity was found in 24 cases (60\%).

On DWI, lesions in 38 cases (95\%) showed true diffusion restriction with low $\mathrm{ADC}$ value while 
in two cases, the lesion showed facilitated diffusion (5\%) with high ADC value. (Table 2).

In our study, highly statistically significant difference was found between benign and malignant lesions according to $\mathrm{ADC}$ value $\left(\mathrm{x}_{10}^{-3}\right)$. The $\mathrm{ADC}$ values in the malignant lesions ranged between $0.6-1.31 \times 10^{-3}$ and in the benign lesions 1.31$2.05 \times 10^{-3}$

The ROC curve for ADC value as a diagnostic marker between malignant lesions and benign lesions shows that the best cut-off point for ADC value was found $\leq 1.31$ with sensitivity of $100.0 \%$, specificity of $95 \%$ and area under curve (AUC) of $99.8 \%$.

Out of 40 cases, 38 cases were proved urinary bladder carcinoma (95\%) and only two cases $(5 \%)$ were diagnosed as benign entity (pseudo tumor) (Fig. 3). 10 cases were squamous cell carcinoma (25\%) (Fig. 1) and 28 cases urothelial carcinoma $(70 \%)$ by histopathological correlation. (Fig. 2).

Out of these 38 cases, six lesions were stage T 1 (15.8\%), eight lesions were stage T2 (21\%), sixteen lesions were stage T3 $(42.1 \%)$ and only eight lesions were stage T4 (21.1\%).

As regards histological grading, 2 cases were grade I $(5.3 \%), 14$ cases were grade II $(36.8 \%)$ and 22 cases were grade III (57.9\%). The ROC curve shows that the best cut-off point for ADC value to differentiate between cases with grade 1 and 2 from grade 3 cases was found $\leq 0.84$ with sensitivity of $81.82 \%$, specificity of $100.0 \%$ and area under curve (AUC) of $81.8 \%$. (Table 3 ) and (Fig. 5).

Regarding the detection of urinary bladder carcinoma the sensitivity, specificity, and accuracy for differentiating superficial from invasive tumors using T2 images alone and combined use of T2 and DW images were $62.5 \%, 66.7 \%, 63.2 \%$ and $100 \%, 100 \%, 100 \%$ respectively.

The specificities and accuracy in differentiating Stage Tis to T1 Tumors from T2 to T4 Tumors obtained by using DW images plus T2-weighted images were significantly better than using T2weighted images alone. Although, the sensitivity by using $\mathrm{T} 2$-weighted is high reaching $62.5 \%$, however it reached $100 \%$ when DW images alone or DW plus T2-weighted images (Fig. 4).
Table (1): Age and sex distribution of the study group.

\begin{tabular}{ccc}
\hline & No. & $\%$ \\
\hline Age (years): & & \\
$\quad \leq 50$ years & 18 & 45.0 \\
$\quad>50$ years & 22 & 55.0 \\
Range [Mean \pm SD] & $30-75[52.85 \pm 13.81]$ \\
Sex: & & \\
Female & 8 & 20.0 \\
Male & 32 & 80.0 \\
\hline Total & 40 & 100.0 \\
\hline
\end{tabular}

Table (2): DWI distribution of the study group.

\begin{tabular}{lll}
\hline DWI & No. & $\%$ \\
\hline $\begin{array}{l}\text { Not restricted } \\
\text { Restricted }\end{array}$ & 2 & 5.0 \\
\hline Total & 38 & 95.0 \\
\hline
\end{tabular}

Table (3): Relation between histological grading and ADC value $\left(\times 10^{-3}\right)$

\begin{tabular}{ccccc}
\hline \multirow{2}{*}{$\begin{array}{c}\text { Histological } \\
\text { grading }\end{array}$} & \multicolumn{2}{c}{ ADC value $\left(\times 10^{-3}\right)$} & \multicolumn{2}{c}{ ANOVA } \\
\cline { 3 - 5 } & Mean \pm SD & Range & F & $p$-value \\
\hline G1 & $1.11 \pm 0.00$ & $1.11-1.11$ & 4.071 & $0.027^{*}$ \\
G2 & $0.97 \pm 0.06$ & $0.91-1.06$ & & \\
G3 & $0.83 \pm 0.14$ & $0.60-1.20$ & & \\
\hline
\end{tabular}

- This table shows statistically significant relation between histological grading and $\mathrm{ADC}$ value $(\mathrm{x} 10)$

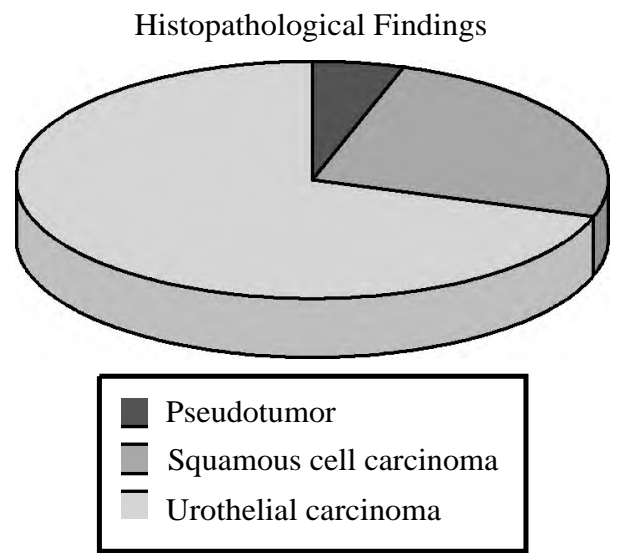

Fig. (1): Histopathological diagnosis of the study group.

No risk factor of bladder malignancy could be detected. Two weeks later, pelvic U/S was performed and a urinary bladder mass was reported. One week later, the patient wasscheduled to perform pelvic MR examination with results as follows: (A) Axial T2WI (B) Coronal T2WI show a sizeable mass (measures $5.4 \times 6.2 \times 6 \mathrm{~cm}$ ) seen at the right 
lateral urinary bladder wall protruding into its lumen with lobulated outline displaying bright signal on T2WI. It shows true restricted diffusion evident by high signal intensity in the diffusion weighted images (C) Axial DWI, with corresponding low $\mathrm{ADC}$ values in ADC map (D) Axial ADC map, with mean ADC $0.9 \times 10^{-3} \mathrm{~mm}^{2} / \mathrm{sec}$. Few foci of urinary bladder wall disruption (muscle layer) are noted with minimal extension into the perivesical fat for few milli meters. The prostate is mildly enlarged with hypointensity at the right peripheral zone at mid, apical and basal protrusion (refer to dotted arrow in image. (b) with no corresponding frank diffusion restriction, suggestive of prostatitis.
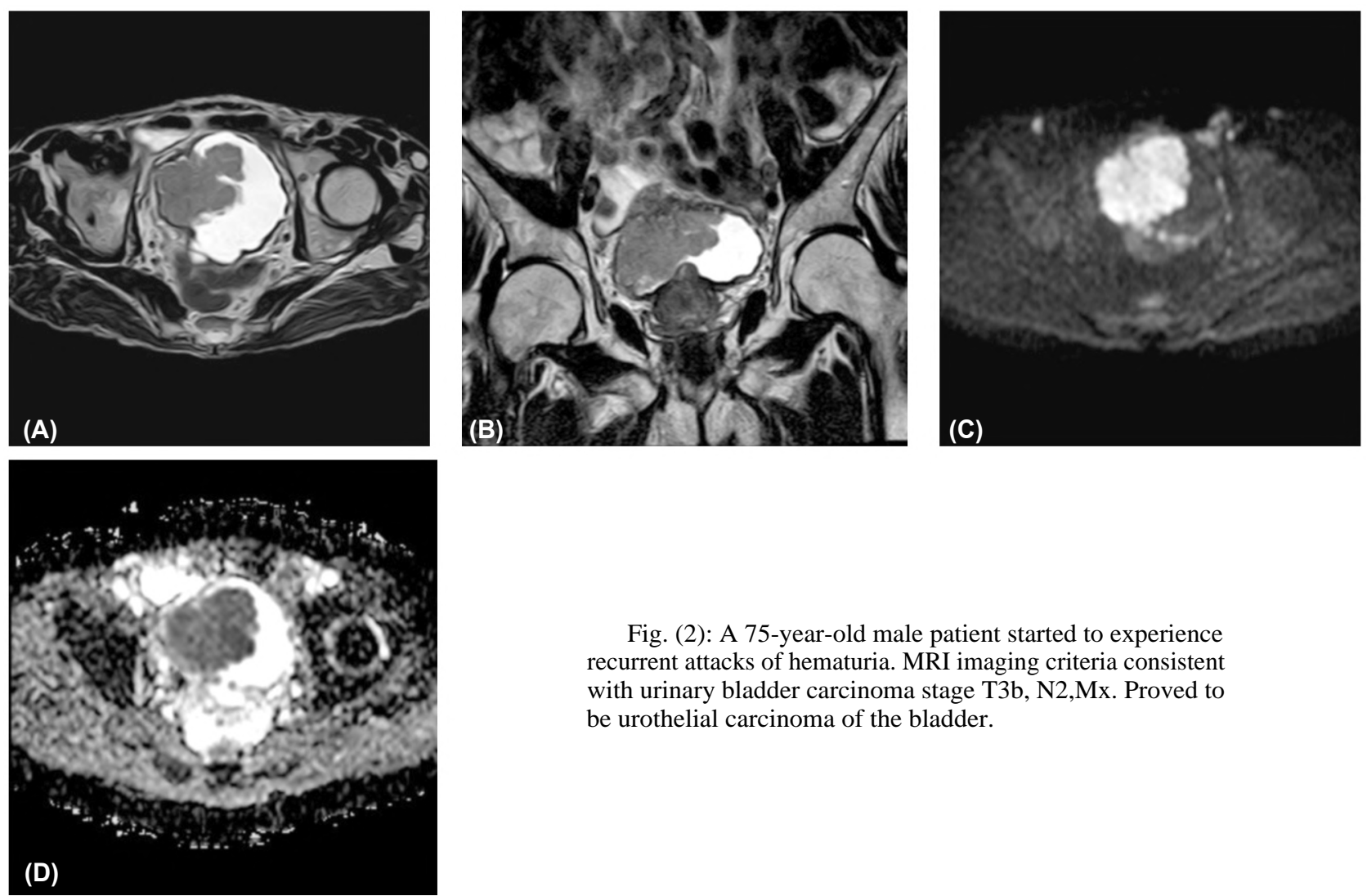

Fig. (2): A 75-year-old male patient started to experience recurrent attacks of hematuria. MRI imaging criteria consistent with urinary bladder carcinoma stage T3b, N2,Mx. Proved to be urothelial carcinoma of the bladder.

She didn't suffer from any constitutional symptoms and did respond to antibiotics. U/S revealed circumferential mural thickening reaching maximum thickness of $6 \mathrm{~mm}$ with a focal sessile mass lesion seen at the bladder dome. Pelvic MR was performed. (A) Axial T2WI (B) Sagittal T2WI confirmed the previous finding of circumferential regular mural thickening reaching $6 \mathrm{~mm}$ with a focal sessile mass at the dome of the bladder measuring about $2 \times 1 \mathrm{cms}$ in TR $\mathrm{x}$ AP dimensions displaying bright signal on $\mathrm{T} 2$ with hypo intense rim. No true diffusion restriction was noted on axial DWI (C) and axial ADC (D). No sizable lymphadenopathy noted and the other pelvic organs were free. Cystoscopy with cytology were performed and revealed inflammatory cells with no neoplastic cells, suggesting benign nature of (Inflammatory the lesion pseudo-tumor).

He presented by recurrent acute attacks of gross hematuria and bilateral loin pain. Pelvic U/S re- vealed fungating heterogeneous hypoechoic soft tissue mass lesion involving the right lateral wall of the urinary bladder. (A) Axial T2WI poorly defined endophytic fungating soft tissue mass involving the right lateral wall and trigone of the urinary bladder measuring about $8.6 \mathrm{~cm}$ in maximum diameter displaying inhomogeneous hyperintense signal on T2WI with focal invasion of the perivesical fat planes along the posterolateral wall of the urinary bladder (stage T3). (B) It showed evidence of restricted diffusion evident by high signal intensity on the axial DWI, the mass is seen encasing the ureteric orifice of low signal intensity with no definite invasion into the perivesical fat planes (stage T2). Corresponding low ADC values on axial ADC map (C) is noted with mean ADC value measures $0.89 \times 10^{-3} \mathrm{~mm}^{2} / \mathrm{sec}$. The locoregional staging of the bladder mass lesion in T2WIs was incorrectly shifted to be stage T3. While findings of DWIs re-correct the loco-regional staging to be stage T2 that were matched with 
pathological findings. In addition, the ADC value is categorized as grade III, which matched with the pathological fiindings as well.
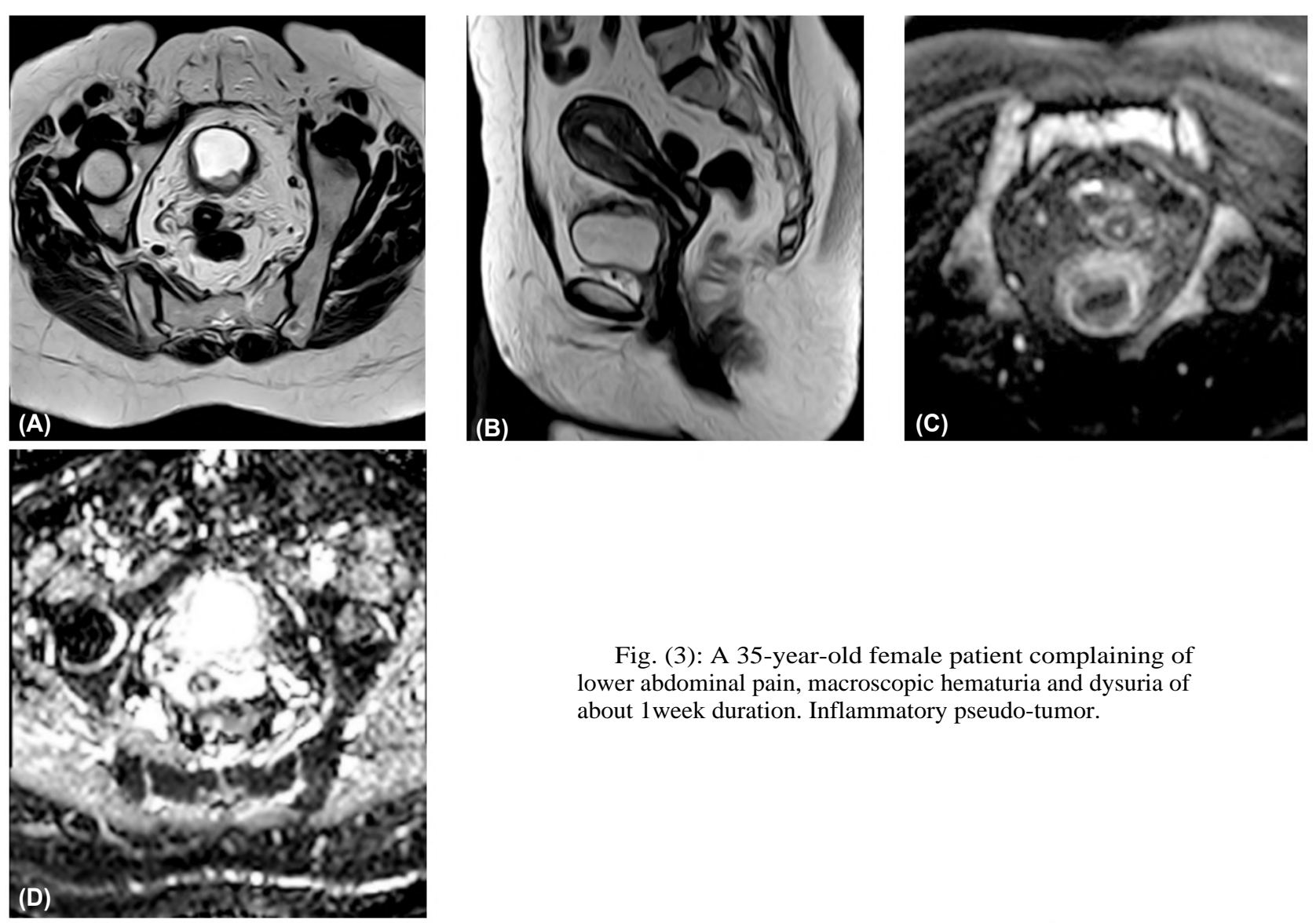

Fig. (3): A 35-year-old female patient complaining of lower abdominal pain, macroscopic hematuria and dysuria of about 1week duration. Inflammatory pseudo-tumor.
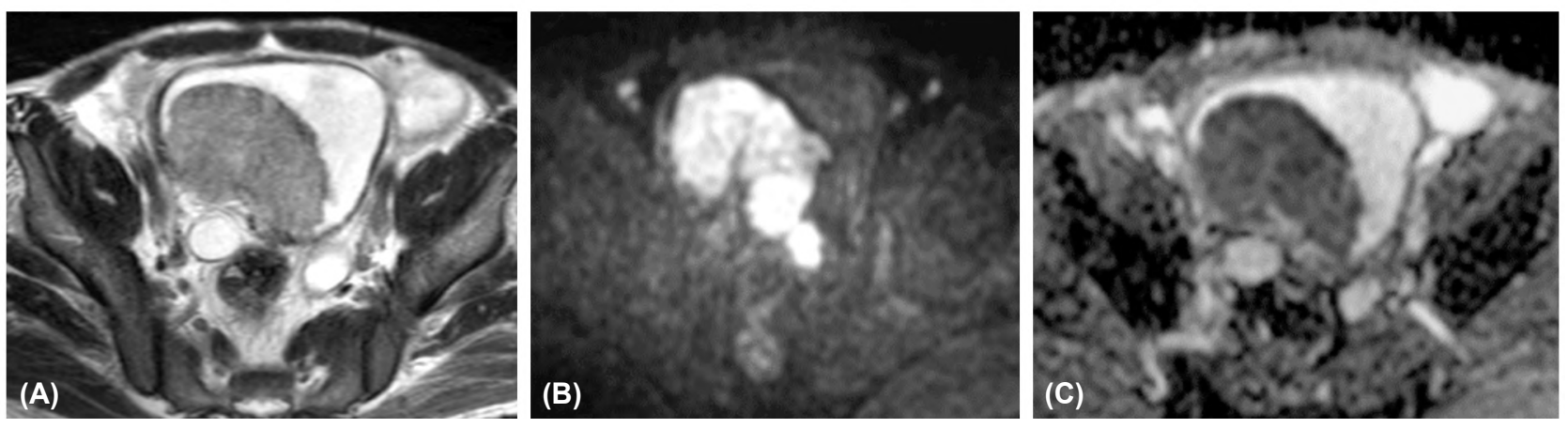

Fig. (4): 44-year-old male patient; heavy smoker for 20 years with history of chronic infection by Schistosomahematobium. Histopathological staging revealed Squamous cell carcinoma: T2, Grade: III.

The patient had a CT examination followed by an MRI. (A) Axial post contrast CT revealed a heterogeneous soft tissue mass lesion along the right lateral wall of the urinary bladder with possible per vesical fat plane invasion. (B) Axial T2WI revealed a poorly defined fungating soft tissue mass lesion involving the right lateral wall of the urinary bladder measuring about $5 \mathrm{~cm}$ in maximum diameter displaying inhomogeneous hyper-intense signal intensity on T2Ws with indistinct normal low signal intensity line of the bladder wall and an exophyticextravesical component invading the perivesical fat planes (stage T3).(C)) axial DWI revealed true diffusion restriction with corresponding low $\mathrm{ADC}$ values in ADC map. (D) Axial ADC with mean $A D C$ value of $0.93 \times 10^{-3} \mathrm{~mm}^{2} / \mathrm{sec}$. The patient underwent radical cystectomy with pathological findings were reported as Squamous carcinoma, Stage T3, Grade III. Findings of CT, T2 \& DWIs were matched with pathological findings regarding the loco-regional staging of the urinary bladder mass lesion (stage T3). 

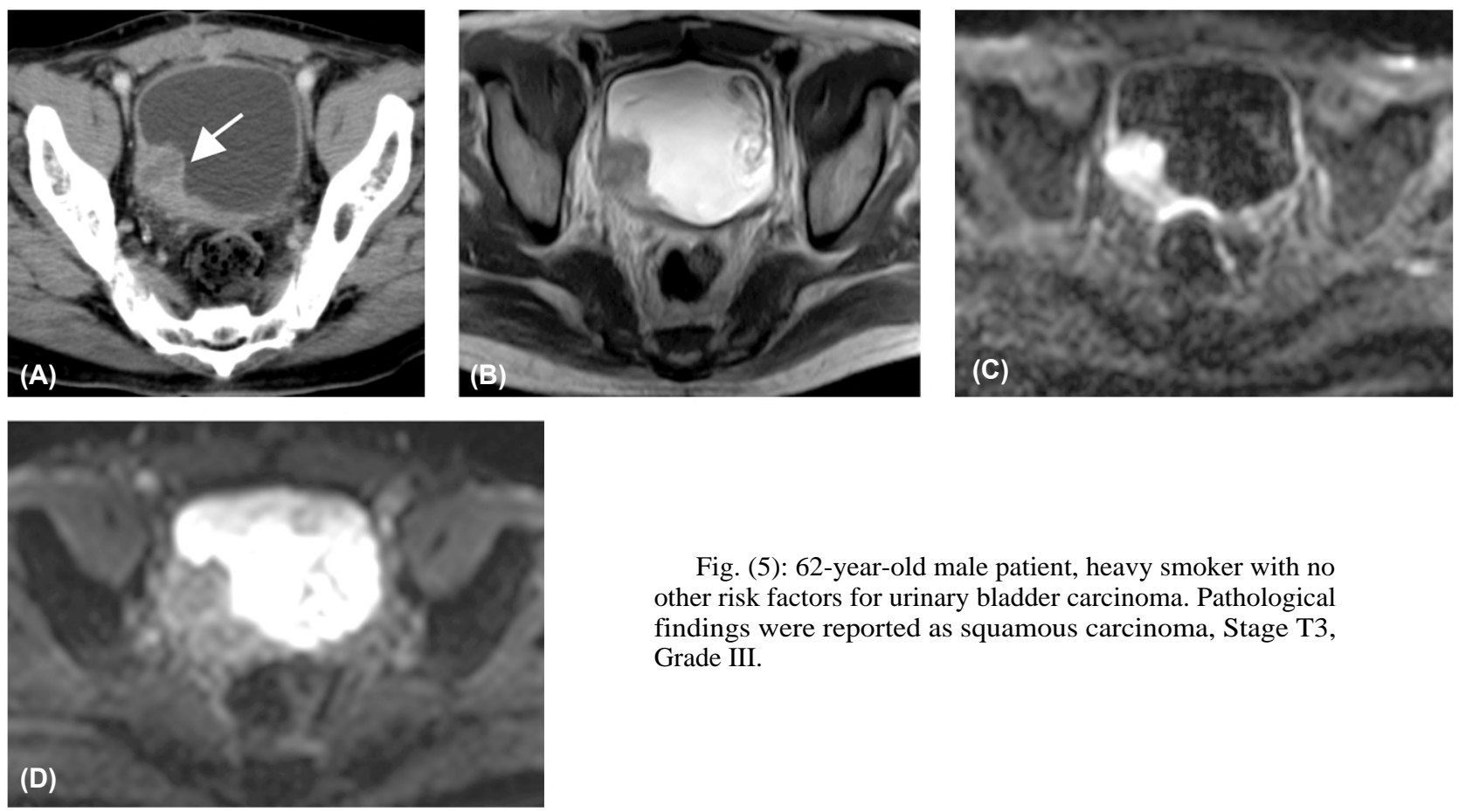

Fig. (5): 62-year-old male patient, heavy smoker with no other risk factors for urinary bladder carcinoma. Pathological findings were reported as squamous carcinoma, Stage T3, Grade III.

\section{Discussion}

Urinary bladder cancer is one of the most common malignant tumors of the urinary tract in both men and women.Accurate preoperative staging and grading is of utter importance in choosing the appropriate treatment plan [7]. The depth, extension and tumor grade will determine the treatment plan either transurethral resection (TUR) with or without neo-adjuvant chemotherapy or photodynamic therapy, or radical cystectomy, radio-therapy, chemotherapy, or a combination of multiple lines of treatment [8]. Also, detection of any extra-vesical extension of $\mathrm{BC}$ is important, as patients with nonorgan confined tumors have higher recurrence rates and decreased survival [3].

$\mathrm{CT}$ has the hazards of ionizing radiation. Contrast agents used in CT and MR imaging can have adverse effects mainly contrast induced nephropathy in CT and nephrogenic systemic fibrosis in MR. Cystoscopy and transurethral endoscopic ultrasonography are invasive maneuvers [9]. Several reports investigated the ability of DW MRI to distinguish the cell type, stage and grade of $\mathrm{BC}$ as a non-invasive method [9].

The effectiveness of diffusion-weighted (DW) MR imaging in detecting malignant lesions with the use of apparent diffusion coefficient (ADC) value characterizing tumor grades has been recently proposed [10].
Many researches have reported low ADC values in different malignant lesions due to packed cellularity and large cellular size [11].

In our study, as regards the detection of urinary bladder carcinoma, the sensitivity, specificity, and accuracy for differentiating superficial from invasive tumors using T2 images solely and combined use of T2 and DW images were $62.5 \%, 66.7 \%$, $63.2 \%$ and $100 \%, 100 \%, 100 \%$ respectively. This is in keeping with Takeuchi $\mathrm{M}$ et al., [12], that revealed that the overall accuracy of $\mathrm{T}$ stage diagnosis was $67 \%$ for T2-weighted images alone, $88 \%$ for T2-weighted plus DW images, 79\% for T2weighted plus contrast-enhanced images, and $92 \%$ for all three image types together.

In our study, highly statistically significant difference was found between benign and malignant lesions according to $\mathrm{ADC}$ value $\left(\mathrm{x} 10^{-3}\right)$. With $\mathrm{ADC}$ values in the malignant lesions ranging between $0.6-1.31 \times 10^{-3} \mathrm{~mm}^{2} / \mathrm{s}$ (mean $0.94 \times 10^{-3} \mathrm{~mm}^{2} / \mathrm{s}$ ) and in the benign lesions $1.31-2.05 \times 10^{-3} \mathrm{~mm}^{2} / \mathrm{s}$ (mean $1.7 \times 10^{-3} \mathrm{~mm}^{2} / \mathrm{s}$ ) Our study is comparable with Rima S. Al Johi et al. [13] were the mean ADC of malignant tumors was $0.78 \times 10^{-3} \mathrm{~mm}^{2} / \mathrm{s}$.

In our study, the ROC curve for ADC value as a diagnostic marker between malignant lesions and benign lesions shows that the best cut-off point for ADC value was found $\leq 1.31$ with sensitivity of $100.0 \%$, specificity of $95 \%$ and area under curve 
(AUC) of $99.8 \%$. This is approving with Avcu et al. [14] who reported cut-off ADC value of $1.5 \mathrm{x}$ $10^{-3} \mathrm{~mm}^{2} / \mathrm{s}$ with nearly slightly lower sensitivity (94.1\%) and almost the same specificity (95.7\%).

The cut-off value in the ROC curve for discriminating malignant and benign lesions was $\leq 1 \mathrm{x}$ $10^{-3} \mathrm{~mm}^{2} / \mathrm{s}$ with $94.5 \%$ sensitivity and $87.5 \%$ specificity according to Rima S. Al Johi et al. [13]

The sensitivity in differentiating Stage Tis to T1 Tumors from T2 to T4 Tumors using T2 weighted was $62.5 \%$. Yet, it reached $100 \%$ after combing both DW and T2- weighted images. According to Al Johi RS et al., [13] proper T staging of BC was better by using both DWI to T2WI showing higher accuracy (68.5\%) than T2WI alone (63\%). The results of the Huan-Jun et al. [15] study also showed that the sensitivities, specificities and accuracy obtained by using both T2WI with DW images was significantly more precise than those obtained by using only $\mathrm{T} 2$-weighted images .

In our study, the mean ADC value of G1 and G2 tumors were much higher than that of G3 tumors. Our results are in keeping with those reported by Zytoon et al., [16] however in their study all G3 tumors had an ADC less than $1.0 \mathrm{x}$ $10^{-3} \mathrm{~mm}^{2} / \mathrm{sec}$, whereas in our study all G3 tumors had an ADC value less than $1.2 \times 10^{-3} \mathrm{~mm}^{2} / \mathrm{sec}$ with mean $\mathrm{ADC}_{-3}$ value in for $\mathrm{G} 3$ tumors being less than $0.97 \times 10^{-3} \mathrm{~mm}^{2} / \mathrm{sec}$. In our study the cut-off point for ADC value to distinguish grade 1 and 2 cases from grade 3 cases was found $\leq 0.84$ with sensitivity of $81.82 \%$, specificity of $100.0 \%$ and area under curve (AUC) of $81.8 \%$. In a study by Al Johi RS et al. [13], the cut-off ADC value that differentiated high grade from low grade tumors was $0.9 \times 10^{-3} \mathrm{~mm}^{2} / \mathrm{s}$. Avcu et al., [14] study reported the cut-off value as $1.135 \times 10^{-3} \mathrm{~mm} 2 / \mathrm{s}$. The inverse relationship between ADC values and tumor grade was also reported by Takeuchi $\mathrm{M}$ et al. [12]. The ADC of low-grade tumors (1.112 \pm $\left.0.159 \times 10^{-3} \mathrm{~mm}^{2} / \mathrm{s}\right)$ was significantly $(p<0.001)$ higher than those of high-grade tumors $(0.772 \pm$ $\left.0.091 \times 10\left(^{-3}\right) \mathrm{mm}\left({ }^{2}\right) / \mathrm{s}\right)$ according to Wang et al. [19], this is also in keeping with our results.

In our study no statistically significant difference was found between the ADC values of different cell types, this could be attributed to the relatively small sample used. However our results are matching with several other researches including Al Johi RS et al. [13] research as well as Sherif MF et al. [17]. All showing that ADC values couldn't differentiate between the different histological subtypes of BC.
In our study, all bladder carcinomas were clearly visible in DWI as a hyper-intense signal relative to the bladder wall and surrounding tissue with $100 \%$ sensitivity similar to other researchers including HM Abdel-Rahman et al. [18] and Al Johi RS et al. [13]. Using DW-MR imaging for urinary bladder carcinoma detection has been reported by Wang et al. [19]. The sensitivity of DW imaging in that study was $100 \%$ for detection of carcinomas. However, that study had several limitations including: Limited number of patients (15 patients) and also that some of the cases were post-biopsy, which could have affected the results. Similar data were reported by Eman et al. [20]. While in another study done by Barrett et al. [21] on patients complaining of hematuria the sensitivity, specificity and accuracy values of DW-MR imaging were found 90\%, 93\% and $91 \%$ respectively. He also reported that DWMR images can provide extra information such as the lesion size, number, and location which can help the surgeons prior to conventional cystoscopy.

According to El-Assmy et al. [22], the sensitivity, specificity and accuracy of DW-MRI for identifying bladder tumors were $91.6 \%, 91.3 \%$ and $91.5 \%$ respectively in follow-up of bladder cancer post TUR. The authors deduced that there was no significant difference between DW-MRI and cystoscopy; as DW-MRI has a high accuracy in characterizing post-TUR inflammatory changes vs bladder tumors, which is similar to that of cystoscopy. Thus, DW-MRI can be used as a first-line noninvasive diagnostic tool in follow-up of patients after TUR.

We agree with Barsoum et al. [8] that the two main pitfalls of DW-MR imaging include inability to visualize the urethral lumen, which is easily assessed by the conventional cystoscopy as well as is that in the presence of any metal prosthesis or implants inevitable metallic artifact will hinder proper assessment. In addition, post-interventional hemorrhage or therapy may lead to improper characterization.

The main limitation of the present study is that a larger number of the included cases were advanced stage tumors and large sized lesions (mean $5.56 \mathrm{~cm}$ ), and this could explain the high sensitivity, specificity and accuracy of DW-MR imaging for differentiating Tis to T2 tumors from T3 to T4 tumors. However, further studies are needed for better assessment of the role of diffusion weighted imaging in early diagnosis, characterization as well a staging of urinary bladder carcinoma. 
However, DW-MRI has many advantages including short acquisition time, being a non-invasive technique without non-ionizing radiation. Also, DWI can be performed without breath-holding, thus allowing examination of ill, old and obese patients who have difficulty in breath holding. DW-MRI is considered as an important marker for cellular impaction, and thus can be used as an alternative tool in diagnosis, follow-up and determining therapy response of bladder tumors.

\section{Conclusion:}

In conclusion, DW-MRI is a safe, accurate and non-invasive method in detection and local staging of urinary bladder carcinoma as well as histological grading of the urinary bladder carcinoma.

\section{References}

1- IBRAHIM A.S., KHALED H.M., MIKHAIL N.N., BARAKA H. and KAMEL H.: Cancer incidence in Egypt: Results of the national population-based cancer registry program. J. Cancer Epidemiol., 2014: 437971, 2014

2- GREEN D.A., RINK M., HANSEN J., et al.: Accurate preoperative prediction of non-organ-confined bladder urothelial carcinoma at cystectomy. BJU Int., 111: 404$411,2013$.

3- LEE M., SHIN S.J., OH Y.T., et al.: Non-contrast magnetic resonance imaging for bladder cancer: Fused high b-value diffusion-weighted imaging and T2-weighted imaging helps evaluate depth of invasion. Eur. Radiol., 27: 37523758, 2017.

4- THOENY H.C., FORSTNER R. and De KEYZER F.: Genitourinary applications of diffusion-weighted MR imaging in the pelvis. Radiology, 263: 326-342, 2012.

5- AFAQ A., KOH D.M., PADHANI A., van AS N. and SOHAIB S.A.: Clinical utility of diffusion-eighted magnetic resonance imaging in prostate cancer. BJU Int., 108: 1716-1722, 2011.

6- KOBAYASHI S., KOGA F. and YOSHIDA S.: Diagnostic performance of diffusion-weighted magnetic resonance imaging in bladder cancer: Potential utility of apparent diffusion coefficient values as a biomarker to predict clinical aggressiveness. Eur. Radiol., 21: 2178-2186, 2011.

7- ERLICH A. and ZLOTTA A.R.: Treatment of bladder cancer in the elderly. Investig. Clin. Urol., 57 (1): 26-35, 2016.

8- BARSOUM N., TALAAT M. and SARAYA S. Can diffusion-weighted MRI predict the histological grade of urinary bladder carcinoma?. KasrAliny Medical Journal, 23 (2): 86-95, 2017.

9- AMET S., LAUNAY-VACHER V., CLÉMENT O., et al.: Incidence of nephrogenic systemic fibrosis in patients undergoing dialysis after contrast-enhanced magnetic resonance imaging with gadolinium-based contrast agents:
The Prospective Fibrose Nephrogénique Systémique study. Invest. Radiol., 49 (2): 109-115, 2014.

10- OHNO Y., NISHIO M., KOYAMA H., et al.: Dynamic contrast-enhanced CT and MRI for pulmonary nodule assessment. AJR. Am. J. Roentgenol., 202: 515-529, 2014.

11-HOSSAM M.A., INAS M.E., ESAM A.E., et al.: The role of diffusion-weighted magnetic resonance imaging in $\mathrm{T}$ staging and grading of urinary bladder cancer. The Egyptian Journal of Radiology and Nuclear Medicine, 46 (3): 741-747, 2015.

12- TAKEUCHI M., SASAKI S., ITO M., et al.: Urinary Bladder cancer: Diffusion weighted MR imaging-accuracy for diagnosing $\mathrm{T}$ stage and estimating histologic grade. Radiology, 251: 112-121, 2009.

13- AL JOHI R.S1, SEIFELDEIN G.S1, MOEEN A.M2, ABOULHAGAG N.A3, MOUSSA EM1, HAMEED D.A2 and IMAM H.M2: Diffusion weighted magnetic resonance imaging in bladder cancer, is it time to replace biopsy? Central European Journal of Urology, 16 Jan 71 (1): 3137, 2017.

14- AVCU S., KOSEOGLU M.N., CEYLAN K., BULUT M.D. and UNAL O.: The value of diffusion-weighted MRI in the diagnosis of malignant and benign urinary bladder lesions. Br. J. Radiol., 84: 875-882, 2011.

15- HUAN-JUN W., MARGARET H.P., YAN G., et al.: Diffusion weighted MRI in bladder carcinoma: The differentiation between tumour recurrence and benign changes after resection. Abdomen Imaging J., 39 (1): 135-141, 2014.

16- ZYTOON A.A., SAMEH M.A. and WALAA A.A.: Role of magnetic resonance in evaluation of urinary bladder cancer. Menoufia Medical Journal, 30 (1): 104-109, 2017.

17- SHERIF M.F.: The value of diffusion weighted MR imaging in $\mathrm{T}$ staging and correlation with histologic grading in urinary bladder cancer. Egypt J. Radiol. Nucl. Med., 46: 189-194, 2015.

18- ABDEL-RAHMAN H.M., EL FIKI I.M., DESOKY E.A.E., ELSAYED E.R. and ABDSAMAD K.M.: The role of diffusion-weighted magnetic resonance imaging in T staging and grading of urinary bladder cancer. Egypt J. Radiol. Nucl. Med., 46: 741-747, 2015.

19-WANG H., GUAN J., GUO Y., et al.: Estimation of bladder carcinoma histologic grade with diffusion-weighted MR imaging. Eur. Soc. Radiol., 138: 409-414, 2014.

20- EMAN F.D., OSAMA L.N. and EMAN A. S.H.G.: Assessing the validity of Prostate Imaging Reporting and Data System version 2 (PI-RADS v2) scoring system in diagnosis of peripheral zone prostate cancer. Eur. J. Radiol. Open., 4: 19-26, 2017.

21- BARRETT T., TURKBEY B. and CHOYKE P.L.: PIRADS version 2: what you need to know. Clin. Radiol., 70: 1165-1176, 2015.

22- EL-ASSMY A., ABOU-EL-GHAR M.E., REFAIE H.F., et al.: Diffusion-weighted MR imaging in diagnosis of superficial and invasive urinary bladder carcinoma: A preliminary prospective study. Scientific World Journal, 8: 364-370, 2008. 


\section{قيمة الرنين المغناطيسى باستخدام خاصية الانتشار المرجح

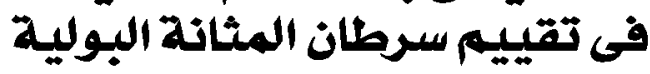

سرطان المثانة البولية هو رابع أكثر شيوعاً بين الذكود والعاشر بين الإناث. لديها معدل تكرار عالية لذالك تتطلب الإدارة الأولية المناسبة.

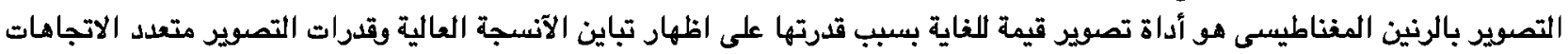
مما يسمع بتصوير أفضل للأنسجة. الهدف من البحث: هو تقييم قيمة التصوير بالرنين المغناطيسى المرجح الانتشار فى تثخيص سرطان المثانة البولية وتنظيمه، مع أخذ التثخيص الباثقلوجى كمرجع. البهث:

التصوير بالرنين المغناطيسى لديه العديد من المزايا بما فى ذلك وقت قصير اقتناء، ويجرى تقنية. دون حبس النفس، كما يسمع بفصص بدون الإشعاع المؤين.

تم مؤخراً اقتراح فعالية التصوير بالرنين المفناطيسى المرجح الانتشار فى الكشف عن الآفات الخبيثة باستخدام قيمة معامل الانتشار

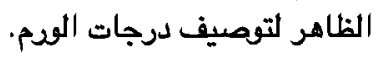
لا تزال الخزعة عبر مجرى البول هو المعيار تاذهبى للتشخيص لكن تثمل خطودة النزيف. تشمل الأشعة المقطعية على مخاطر الأشعة الايونية وأضرار الصبغة على الكلى مما قد يؤدى إلى اعتلال فى وظائف كلى ـ يثبت البحث

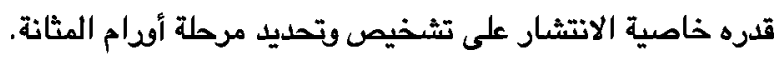

العيب الرئيسى اللرنين هى عدم قدرته على تصوير مجرى البول بالاضافة إلى أن وجود أى معدن يؤثر على جودة الصورة بالاضافة لذلك،

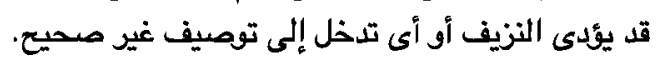

